\title{
Hypnotizability and Catechol-O-Methyltransferase (COMT) polymorphysms in Italians
}

\section{Silvano Presciuttini ${ }^{1}$, Alessandro Gialluisi ${ }^{1,2}$, Serena Barbuti ${ }^{3}$, Michele Curcio ${ }^{3}$, Fabrizio Scatena ${ }^{3}$, Giancarlo Carli ${ }^{1,4}$ and Enrica L. Santarcangelo ${ }^{1 *}$}

\author{
Laboratory of Cognitive and Behavioral Neurosciences, Department of Translational Research and New Technologies in Medicine and Surgery, \\ University of Pisa, Pisa, Italy \\ ${ }^{2}$ Language and Genetics Department, Max Planck Institute for Psycholinguistics, Nijmegen, Netherlands \\ ${ }^{3}$ Immunohematology Unit, Azienda Ospedaliera-Universitaria Pisana, Pisa, Italy \\ ${ }^{4}$ Department of Medicine, Surgery and Neuroscience, University of Siena, Siena, Italy
}

\section{Edited by:}

Patrik Vuilleumier, University Medical Center and University Hospital

Geneva, Switzerland

Reviewed by:

Audrey Vanhaudenhuyse, University Hospital of liège, Belgium

Vilfredo De Pascalis, La Sapienza

University of Rome, Italy

Yann Cojan, Laboratory of Neurology

and Imaging of Cognition, Switzerland

${ }^{*}$ Correspondence:

Enrica L. Santarcangelo, Laboratory of

Cognitive and Behavioral

Neurosciences, Department of

Translational Research and New

Technologies in Medicine and Surgery,

University of Pisa, Via San Zeno 31,

56127 Pisa, Italy

e-mail: enricals@dfb.unipi.it
Higher brain dopamine content depending on lower activity of Catechol-OMethyltransferase (COMT) in subjects with high hypnotizability scores (highs) has been considered responsible for their attentional characteristics. However, the results of the previous genetic studies on association between hypnotizability and the COMT single nucleotide polymorphism (SNP) rs4680 (Val ${ }^{158} \mathrm{Met}$ ) were inconsistent. Here, we used a selective genotyping approach to re-evaluate the association between hypnotizability and COMT in the context of a two-SNP haplotype analysis, considering not only the $\mathrm{Val}^{158}$ Met polymorphism, but also the closely located rs4818 SNP. An Italian sample of 53 highs, 49 low hypnotizable subjects (lows), and 57 controls, were genotyped for a segment of $805 \mathrm{bp}$ of the COMT gene, including Val ${ }^{158} \mathrm{Met}$ and the closely located rs4818 SNP. Our selective genotyping approach had $97.1 \%$ power to detect the previously reported strongest association at the significance level of $5 \%$. We found no evidence of association at the SNP, haplotype, and diplotype levels. Thus, our results challenge the dopamine-based theory of hypnosis and indirectly support recent neuropsychological and neurophysiological findings reporting the lack of any association between hypnotizability and focused attention abilities.

Keywords: hypnotizability, attention, COMT, absorption, selective genotyping, haplotype analysis

\section{INTRODUCTION}

The cognitive trait of hypnotizability (Green et al., 2005) - the ability to accept hypnotic suggestions - has been classically attributed to peculiar characteristics of the supervisory attentional system (Norman and Shallice, 1986; Posner and Fan, 2004) allowing a more flexible attentional control in the subjects scoring high (highs) at hypnotizability scales. In fact, a few neuropsychological (Tellegen and Atkinson, 1974; Zachariae et al., 2000) and genetic studies (Lichtenberg et al., 2000; Raz, 2005; Raz et al., 2006; Szekely et al., 2010) have suggested greater abilities of focused attention in highs with respect to low hypnotizable individuals (lows), based on higher dopaminergic activity.

In the general population, attention seems to be more efficiently controlled in subjects with the Met/Met or Val/Met variant of the single nucleotide polymorphism (SNP) rs4680 at the catechol-O-methiltransferase (COMT) gene than in the homozygous Val/Val individuals (Seamans and Yang, 2004). In fact, the Met/Met variant shows $40 \%$ less enzymatic activity than the $\mathrm{Val} / \mathrm{Val}$ and, thus, is associated with higher dopamine levels in the prefrontal (Roussos et al., 2008) and anterior cingulate cortex (Blasi et al., 2005).

The three association studies conducted so far on the relation between the COMT Val ${ }^{158}$ Met polymorphism and hypnotizability have provided inconsistent results. Two of them (Lichtenberg et al.,
2000; Raz, 2005) applied analysis of variance on the hypnotizability scores in subjects stratified by the COMT genotype. In this approach, a sample of subjects not selected for hypnotizability (thus representing the distribution of this trait in the general population) is genotyped, and ANOVA is used to test the differences of the mean hypnotizability scores among the genotypes. Both studies reported a higher mean score of hypnotizability in heterozygotes (Met/Val) than in both homozygotes (Val/Val, Met/Met), but in one of them the association between hypnotizability and COMT polymorphism was significant in females only (Lichtenberg et al., 2000). On the contrary, the third study (Szekely et al., 2010) using the same approach reported intermediate hypnotizability scores in heterozygotes; these authors also contrasted the highs and lows recruited in the sample for genotype frequencies, and found a significantly higher frequency of the Val allele among highs.

Thus, the first aim of the present study was to re-evaluate the relationship between the rs4680 (Val ${ }^{158} \mathrm{Met}$ ) COMT variant and hypnotizability through a selective genotyping approach.

It should be noticed also that the COMT locus is polymorphic for many other SNPs that may interact in a complex way to determine phenotypic differences among individuals (Diatchenko etal., 2005; Nackley etal., 2006; Roussos etal., 2008). This occurs, for instance, for the coding regions rs4633 
(C/T, synonymous), rs4818 (C/G, synonymous), and $\mathrm{rs} 4680$ (G/A, Val $\left.{ }^{158} \mathrm{Met}\right)$, which are strongly associated with experimental pain sensitivity (Diatchenko et al., 2005). Thus, the second aim of the present study was to conduct the analysis, for the first time on hypnotisability, at the haplotype level, including the two closely located SNPs rs4818 (Leu ${ }^{136} \mathrm{Leu}$ ) and rs4680 ( Val $\left.{ }^{158} \mathrm{Met}\right)$.

\section{MATERIALS AND METHODS SUBJECTS}

After signing an informed consent describing the nature and procedure of the study, 102 unpaid healthy subjects volunteered for the study which was approved by the Ethical Committee of the University of Pisa. Hypnotizability was evaluated according to the Italian version (Weitzenhoffer and Hilgard, 1959; De Pascalis etal., 2000) of the Stanford Hypnotic Susceptibility Scale (SHSS, form A). The participants were 53 highs (19 M, 34 F; SHSS mean score: $10.26+1.04)$ and 49 lows (22 M, 27 F; SHSS mean score: $0.33 \pm 0.59$ ) selected from a database including 1043 students of the Universities of Pisa and Siena (410 M, 633 F). As a control group representative of the general population, 57 umbilical cords (Controls) from the Immuno-hemathology Unit Bank at the Azienda Ospedaliera-Universitaria Pisana, were genotyped anonymously (Controls). Consensus on the employment of the umbilical cords for research had been obtained from mothers at the Azienda Ospedaliera-Universitaria Pisana soon after delivery.

\section{DNA EXTRACTION, AMPLIFICATION AND ANALYSIS}

Genomic DNA was isolated by the QIAamp DNA Blood kit (QIAGEN GmbH, Hilden, Germany) according to manufacture's instructions from highs' and lows' peripheral blood leukocytes. The same was done with umbilical cords samples from (Controls). For privacy requirements, blood samples were coded anonymously. The DNA extracted from $200 \mu \mathrm{l}$ of blood was diluted with $200 \mu \mathrm{l}$ of $\mathrm{H} 2 \mathrm{O}$, quantified by UV measurement at OD $260 \mathrm{~nm}$ and stored at $-20^{\circ} \mathrm{C}$ until further processing. Later, the DNA sample was restored at a normal temperature and underwent a polymerase chain reaction (PCR) aimed at amplifying the target region in the COMT gene, i.e., a portion of $805 \mathrm{bp}$ containing the exon 4 , in which the SNP rs4680 resides. The amplification (performed on a PTC 100 Thermal Cycler, MJ Research, Watertown, MA, USA) was done in $50 \mu$ l reactions containing $5 \mu \mathrm{l}$ of 10X Buffer solution, $0.2 \mu \mathrm{M}$ of each primer (COMTF: 5'-ATCCAAGTTCCCCTCTCTCCACCTG-3'; COMT-R: 5' GTTGGGGCTCACCTCCAAGAGAAGC-3' ${ }^{\prime}$, $0.2 \mathrm{mM}$ deoxynucleoside triphosphates (dNTPs), $1.5 \mathrm{mM}$ of $\mathrm{MgCl} 2,2.5 \mathrm{U}$ Taq DNA Polymerase, Recombinant (Invitrogen by life technologies), and $\sim 100 \mathrm{ng}$ of genomic DNA, along with $\mathrm{H} 2 \mathrm{O}$ to complete the total reaction volume. PCR conditions consisted of an initial denaturation step at $96^{\circ} \mathrm{C}$ for $2 \mathrm{~min}$ followed by 35 cycles on a thermocycler (denaturation at $96^{\circ} \mathrm{C}$ for $30 \mathrm{~s}$, annealing at $68^{\circ} \mathrm{C}$ for $20 \mathrm{~s}$, and extension at $72^{\circ} \mathrm{C}$ for $60 \mathrm{~s}$ ). After specific amplification the PCR fragments were purified using QIAquick PCR Purification microcentrifuge columns. Sequencing reactions were carried out using forward and reverse primers (COMT-F:
5'-ATCCAAGTTCCCCTCTCTCCACCTG-3' and COMT seq, R, $5^{\prime}$-CCTTTTTCCAGGTCTGACAA- $3^{\prime}$ ) and BigDye Terminator v3.1 in accord to protocol (Applied Biosystems, USA). The sequencing were run on the ABI 3130xl Prism Genetic Analyzer (Applied Biosystems) and analyzed using the software SeqScape v.2.5 (Applied Biosystems).

A DNA fragment of $240 \mathrm{bp}$ of the COMT gene containing the well-known non-synonymous SNP rs4680 (G/A at position 472, or $\mathrm{Val}^{158} \mathrm{Met}$ ) was sequenced in highs, lows, and Controls. In addition to rs4680, a second SNP was identified at position 408, namely, the synonymous rs4818 (C/G, or Leu $\left.{ }^{136} \mathrm{Leu}\right)$.

\section{STATISTICAL ANALYSIS}

Adherence of genotype frequencies to Hardy-Weinberg equilibrium was assessed by goodness-of-fit tests. Heterogeneity of allele frequencies among population samples was assessed by contingency-table $\chi^{2}$ analysis. Difference of allele frequency between highs and lows was measured by calculating odds ratio and $95 \%$ confidence limits. Maximum likelihood estimates of twolocus haplotype frequencies were obtained by the expectationmaximization (EM) algorithm (Terwilliger and Ott, 1994). Power analysis was evaluated by the arcsine transformation of Cohen (Cohen, 1988; Motulsky, 2010). All calculations were performed in Excel.

\section{RESULTS}

Table 1 shows the genotypes at the COMT Val ${ }^{158}$ Met polymorphism and the Met allele frequency in highs, lows, and Controls; no heterogeneity of allele frequency was detected $\left(\chi^{2}=4.27\right.$, d.f. $=2$, $p=0.118)$. The odds ratio of the Val allele for highs and lows $(2 \times 2$ table) was 0.7 ; 95\% Confidence Interval: 0.4-1.3.

Table 2 shows the genotype counts of $\mathrm{rs} 4818$ (C/G, or $\left.\mathrm{Leu}^{136} \mathrm{Leu}\right)$ and $\mathrm{rs} 4680$ (G/A, or $\left.\mathrm{Val}^{158} \mathrm{Met}\right)$ in the form of twoSNP genotypes, for each of our three samples. Hardy-Weinberg equilibrium tests were performed for each of the two SNPs, separately for males and females. No significant deviation was detected in any of these subsamples.

The EM algorithm produced the haplotype frequency estimates shown in Figure 1. One of the four possible haplotypes (G_A, in the order rs4818-rs4680) was absent from both highs and lows, meaning complete linkage disequilibrium, whereas it was present at low frequency $(0.02)$ in the control sample.

Table 1 | Genotypes at COMT Val ${ }^{158}$ Met polymorphism in highs, lows, and Controls.

\begin{tabular}{llllll}
\hline Sample type & $\begin{array}{l}\text { MetMet } \\
\text { AA }\end{array}$ & $\begin{array}{l}\text { MetVal } \\
\text { AG }\end{array}$ & $\begin{array}{l}\text { ValVal } \\
\text { GG }\end{array}$ & Total & p(A) \\
\hline highs & 11 & 25 & 17 & 53 & 0.443 \\
$\%$ & 20.8 & 47.2 & 32.1 & & \\
lows & 10 & 16 & 23 & 49 & 0.367 \\
$\%$ & 20.4 & 32.7 & 46.9 & & \\
Controls & 12 & 34 & 11 & 57 & 0.569 \\
\hline
\end{tabular}

${ }^{1}$ Metallele frequency. 
Table 2 | Joint genotype distribution of rs4818 (C/G, or Leu ${ }^{136}$ Leu) and rs4680 (G/A, or Val ${ }^{158}$ Met), in three population samples.

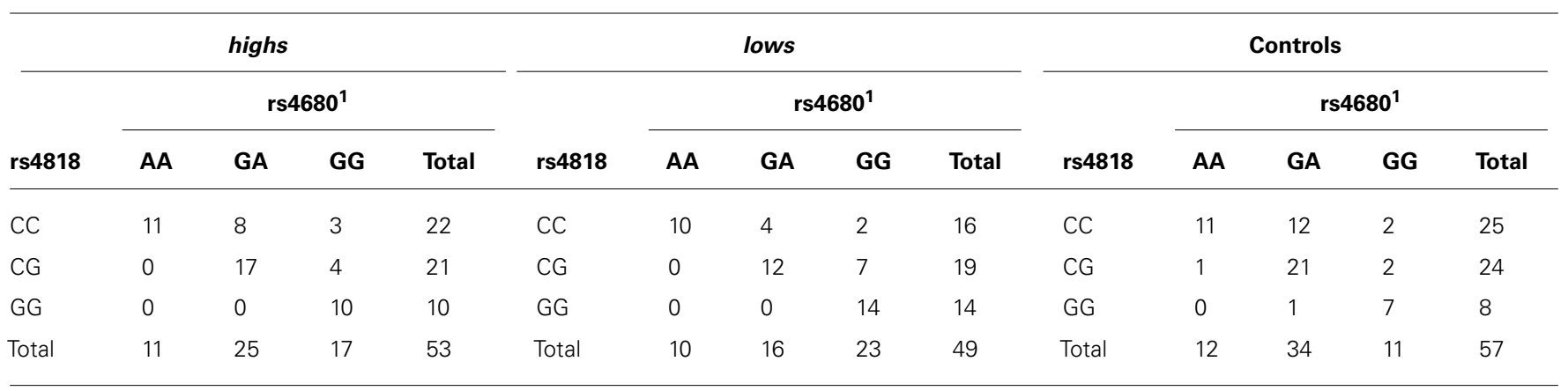

${ }^{1} A A$, (MetMet); GA, (MetVal); GG, (ValVal).

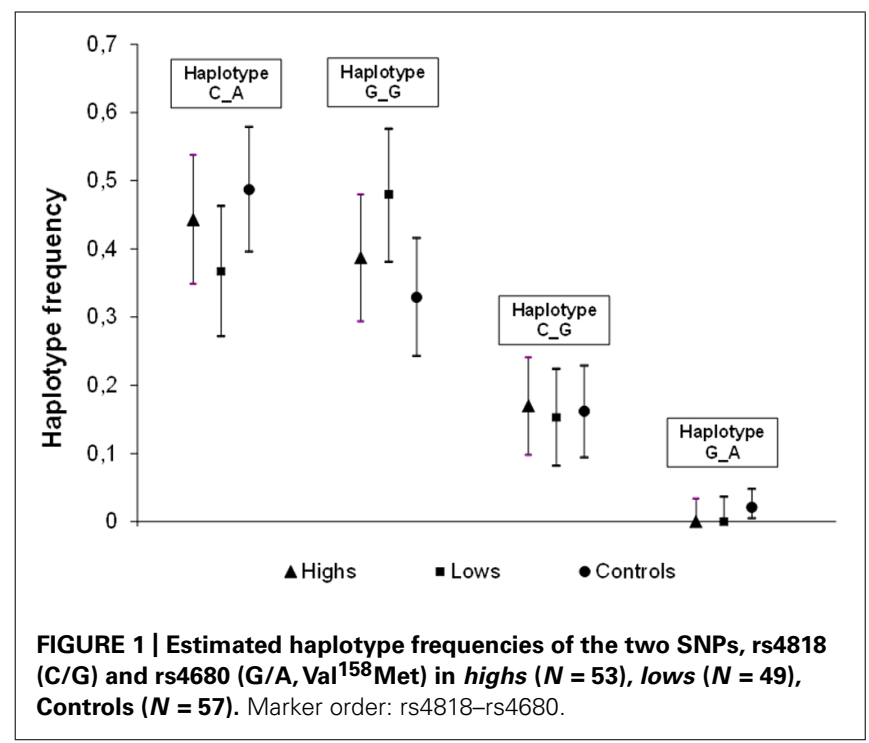

The large overlap of the $95 \%$ confidence intervals of the three samples makes it clear that there is no association between hypnotizability and these COMT haplotypes. Indeed, there was no evidence of heterogeneity $\left(\chi^{2}=3.78\right.$, d.f. $\left.=5, p=0.582\right)$ in highs and lows also for the absolute frequencies of the two-SNP diplotypes.

\section{DISCUSSION}

The present study does not show any association between COMT polymorphisms and hypnotizability at the SNP, haplotype, and diplotype levels.

\section{GENETIC FINDINGS AND NEUROPSYCHOLOGICAL EVIDENCE ON HYPNOTIZABILITY-RELATED ATTENTIONAL ABILITIES}

Previous studies (Lichtenberg et al., 2000; Raz, 2005; Raz et al., 2006; Szekely et al., 2010) presented some evidence of association between the $\mathrm{Val}^{158} \mathrm{Met}$ polymorphism and hypnotisability (Table 3).

The most important discrepancy concerns our results and those reported by Szekely et al. (2010). That work found a significant difference in allele frequencies between highs and lows, but its power was limited by the necessarily small proportion of highs in the samples $(N=19)$, which is due to the distribution of hypnotizability scores in the general population (Balthazard and Woody, 1989; De Pascalis et al., 2000; Carvalho etal., 2008). Our alternative approach of selective genotyping, in which individuals are sampled from the opposite tails of a quantitative trait, can substantially increase the power of population-based associations studies (Schork et al., 2000; Van Gestel et al., 2000).

It should be noted that the odds ratio of the Val allele (recalculated from published data) is 3.0 in the work by Szekely and coll. (Szekely et al., 2010), whereas it is 0.7 in our data, and the $95 \%$ CI do not overlap. The power of our study to detect significant heterogeneity of allele frequency between highs and lows, if their frequency were as in (Szekely et al., 2010), was 97.1\% at the significance level of 5\%, and it was $89.8 \%$ at the significance level of $1 \%$.

Theoretically, the different methods of hypnotic assessment between studies might account for the different results, but we consider this unlikely, as the methods used in the present and in other works provide highly correlated results (Sheehan and McConkey, 1982). Another factor possibly accounting for the discrepancy is a different level of association in different populations; this can happen if the association is caused by a nearby locus that shows variable levels of linkage disequilibrium among populations.

The present results are in line with the findings showing the absence of any hypnotizability-related difference in attentional tests (Varga et al., 2011), and also the absence of significant correlation between COMT polymorphism and executive attention performance as measured by Posner Attentional Network Test (Fossella et al., 2002). Moreover, recent neuropsychological studies contrast the classical view of hypnotizability based on high abilities of focused attention and attribute the hypnotizability-related cognitive characteristics to impaired frontal executive functions inducing a lower capacity to disengage attention from its current focus (Jamieson and Sheehan, 2004; Egner etal., 2005). Finally, the assumption that the larger content of the homovanillic acid (HA) found in highs (Spiegel and King, 1992) depends on reduced DOPA catabolism (responsible for high abilities of focused attention) is weak, as HA is a catabolite of both dopamine and norepinephrine and its content in the cerebrospinal fluid derives from their catabolism in several neural circuits $(\mathrm{Gu}$, 
Table 3 | Genetic association studies between the COMT Val ${ }^{158}$ Met polymorphism and hypnotizability.

\begin{tabular}{|c|c|c|c|c|c|c|c|}
\hline & Sample type & $\begin{array}{l}\text { MetMet } \\
\text { AA }\end{array}$ & $\begin{array}{l}\text { MetVal } \\
\text { AG }\end{array}$ & $\begin{array}{l}\text { ValVal } \\
\text { GG }\end{array}$ & Total & $\mathbf{p}(\mathbf{A})^{1}$ & Remarks \\
\hline \multicolumn{8}{|c|}{ ANOVA based approaches } \\
\hline \multirow[t]{3}{*}{ Lichtenberg etal. (2000) } & Unstratified & 77 & 41 & 19 & 137 & 0.712 & $\begin{array}{l}\text { Association significant in females only; } \\
\text { highest hypnotizability score } \\
\text { in heterozygotes }\end{array}$ \\
\hline & $\%$ & 56.2 & 29.9 & 13.9 & & & \\
\hline & Mean $\mathrm{HS}^{2}$ & 5.2 & 6.6 & 4.5 & & & \\
\hline \multirow[t]{3}{*}{ Raz (2005) } & Unstratified & 18 & 33 & 25 & 76 & 0.454 & $\begin{array}{l}\text { Highest hypnotizability score in } \\
\text { heterozygotes; no significance test } \\
\text { provided }\end{array}$ \\
\hline & $\%$ & 23.7 & 43.4 & 32.9 & & & \\
\hline & Mean HS & 6.1 & 7.6 & 5.9 & & & \\
\hline \multirow[t]{3}{*}{ Szekely et al. (2010) } & Unstratified & 30 & 66 & 31 & 127 & 0.496 & $\begin{array}{l}\text { ANOVA significant for genotype } \\
\text { effect ( } p=0.016) \text {; medium score in } \\
\text { heterozygotes }\end{array}$ \\
\hline & $\%$ & 23.6 & 52.0 & 24.4 & & & \\
\hline & Mean HS & 4.1 & 4.7 & 5.9 & & & \\
\hline \multicolumn{8}{|l|}{ Categorical data analysis } \\
\hline \multirow[t]{4}{*}{ Szekely et al. (2010) } & highs (mean HS $9.3 \pm 1.0$ ) & 1 & 9 & 9 & 19 & 0.289 & $\begin{array}{l}\chi^{2} \text { significant for heterogeneity } \\
(p=0.009) ; \text { Odds Ratio for the } \\
\text { Val allele }(2 \times 2 \text { table })=3.0 ; 95 \% \mathrm{Cl}^{3}: \\
1.4-6.7 \text { (calculated from published data })^{4}\end{array}$ \\
\hline & $\%$ & 5.2 & 47.4 & 47.4 & & & \\
\hline & lows (mean HS $2.6 \pm 0.7$ ) & 15 & 34 & 9 & 58 & 0.552 & \\
\hline & $\%$ & 25.9 & 58.6 & 15.5 & & & \\
\hline
\end{tabular}

${ }^{1}$ Metallele frequency; ${ }^{2}$ Hypnotizability Score; ${ }^{3}$ Confidence Interval; ${ }^{4}$ The corresponding value of our data was $0.7 ; 95 \%$ Cl: 0.4-1.3.

2002) not necessarily including those responsible for focused attention.

\section{MECHANISMS INDEPENDENT OF COMT POLYMORPHISMS POTENTIALLY INVOLVED IN HYPNOTIZABILITY-RELATED ATTENTIONAL CHARACTERISTICS}

The highs' attention seems to be stable rather than flexible. A few authors suggest that the carriers of the Met allele might be comparatively high in cognitive stability, but low in cognitive flexibility (Cools, 2008; Cools and D'Esposito, 2009; Colzato et al., 2010). High flexibility would be associated with great distractibility, while high stability may be related to scarce distractibility (Goschke, 2000), as suggested for highs (Tellegen and Atkinson, 1974; Lichtenberg et al., 2000, 2004; Zachariae et al., 2000; Raz, 2005; Raz et al., 2006). The balance between cognitive flexibility and stability (Cools and D'Esposito, 2009; Darvas and Palmiter, 2011) could depend on the interaction between the dopaminergic circuits of the prefrontal cortex (where the catecholamines metabolism relies mainly on the activity of the COMT) and of the striatum, where the catecholamines metabolism depends mostly on the mono aminooxidase (MAO) enzymatic system (Darvas and Palmiter, 2011).
Actually, polymorphisms in MAO have also been found associated with executive attention and with alerting efficiency (Fossella et al., 2002).Thus, different attentional performance could be accounted for by a peculiar balance between the catecholamines degradation occurring in different brain structures.

However, the existence of multiple subtypes of highs and lows (Balthazard and Woody, 1989; Pekala and Forbes, 1997; Green and Lynn, 2011; Terhune et al., 2011) suggests that it is unlikely that one biological determinant may account for such a complex trait like the susceptibility to hypnosis, and we may expect that several neurotransmitters and neuromodulators influence hypnotizability (Ott et al., 2005; Klinkenberg et al., 2011). Recent evidence suggests a role for nitric oxide (NO) because the hypnotizabilityrelated vascular responses to cognitive and physical stimulation indicate greater NO availability in the highs' vessels (Jambrik et al., 2004; Jambrik et al., 2005). In the brain, endothelial NO is responsible for basal vascular tone, interacts with other mediators in its modulation, and acts as a neurotransmitter after diffusion to the extracellular compartment (Andresen et al., 2006). Using an in vivo brain microdialysis technique, it has been demonstrated that NO significantly increases the release of acetylcholine and decreases the 
release of dopamine in the rat striatum (Guevara-Guzman et al., 1994), while increasing its metabolism (Nabeshima et al., 1987; Löscher et al., 1991). Thus, a greater NO availability modulating both dopamine and acetylcholine production may account for the observed higher HA content in the cerebrospinal fluid (Spiegel and King, 1992), higher arousal (Castellani and Sebastiani, 2008) and greater attentional stability (Colzato et al., 2010) of highs with respect to lows.

\section{CONCLUSION}

The observed absence of any association between hypnotizability and COMT polymorphisms/haplotypes prompts reconsideration of the theory indicating a generally reduced brain DOPA catabolism as responsible for the attentional abilities of the subjects with high hypnotizability. The findings on the nitric oxide vascular availability open frontier research on possible alternative bases.

\section{AUTHOR CONTRIBUTIONS}

Silvano Presciuttini, Giancarlo Carli, and Enrica L. Santarcangelo have designed the study and written the paper; Serena Barbuti, Michele Curcio, and Fabrizio Scatena have performed the DNA analysis; Alessandro Gialluisi and Silvano Presciuttini have done statistical analyses.

\section{ACKNOWLEDGMENTS}

Research funded by the University of Pisa (Fondi di Ateneo). We are grateful to E. Castellani, M. Menzocchi, G. Paoletti, E. Scattina for hypnotic assessment, and to I. Bianco, I. Spinetti, and A. Rocchi for laboratory assistance.

\section{REFERENCES}

Andresen, J., Shafi, N. I., and Bryan, R. M. (2006). Endothelial influences on cerebrovascular tone. J. Appl. Physiol. 100, 318-327. doi: 10.1152/japplphysiol.00937.2005

Balthazard, C. G., and Woody, E. Z. (1989). Bimodality, dimensionality, and the notion of hypnotic types. Int. J. Clin. Exp. Hypn. 37, 70-89. doi: $10.1080 / 00207148908410534$

Blasi, G., Mattay, V. S., Bertolino, A., Elvevåg, B., Callicott, J. H., Das, S., et al. (2005). Effect of catechol-O-methyltransferase val158met genotype on attentional control. J. Neurosci. 25, 5038-5045. doi: 10.1523/JNEUROSCI.0476-05.2005

Carvalho, C., Kirsch, I., Mazzoni, G., and Leal, I. (2008). Portuguese norms for the Waterloo-Stanford Group C (WSGC) scale of hypnotic susceptibility. Int. J. Clin. Exp. Hypn. 56, 295-305. doi: 10.1080/00207140802041850

Castellani, E., and Sebastiani, L. (2008). Manipulation of attention in highly and low hypnotizable individuals: a study on verbal priming. Arch. Ital. Biol. 146, 21-33.

Cohen, J. (1988). Statistical Power Analysis for the Behavioral Sciences. Hillsdale, NJ: Lawrence Erlbaum.

Colzato, L. S., Waszak, F., Nieuwenhuis, S., Posthuma, D., and Hommel, B. (2010). The flexible mind is associated with the catechol-O-methyltransferase (COMT) Val158Met polymorphism: evidence for a role of dopamine in the control of task-switching. Neuropsychologia 48, 2764-2768. doi: 10.1016/j.neuropsychologia.2010.04.023

Cools, R. (2008). Role of dopamine in the motivational and cognitive control of behavior. Neuroscientist 14, 381-395. doi: 10.1177/1073858408317009

Cools, R., and D'Esposito, M. (2009). “Dopaminergic modulation of flexible cognitive control in humans," in Dopamine Handbook, 1st Edn, eds L. Iversen, S. Iversen, S. Dunnett, and A. Bjorklund (Oxford: Oxford University Press).

Darvas, M., and Palmiter, R. D. (2011). Contributions of striatal dopamine signaling to the modulation of cognitive flexibility. Biol. Psychiatry 69, 704-707. doi: 10.1016/j.biopsych.2010.09.033
De Pascalis, V., Russo, P., and Marucci, F. S. (2000). Italian norms for the Harvard Group Scale of Hypnotic Susceptibility, Form A. Int. J. Clin. Exp. Hypn. 48, 44-55. doi: 10.1080/00207140008410360

Diatchenko, L., Slade, G. D., Nackley, A. G., Bhalang, K., Sigurdsson, A., Belfer, I., et al. (2005). Genetic basis for individual variations in pain perception and the development of a chronic pain condition. Hum. Mol. Genet. 14, 135-143. doi: $10.1093 / \mathrm{hmg} / \mathrm{ddi} 013$

Egner, T., Jamieson, G., and Gruzelier, J. (2005). Hypnosis decouples cognitive control from conflict monitoring processes of the frontal lobe. Neuroimage 27, 969-978. doi: 10.1016/j.neuroimage.2005.05.002

Fossella, J., Sommer, T., Fan, J., Wu, Y., Swanson, J. M., Pfaff, D. W., et al. (2002). Assessing the molecular genetics of attention networks. BMC Neurosci. 3:14. doi: 10.1186/1471-2202-3-14

Goschke, T. (2000). "Involuntary persistence and intentional reconfiguration in tasks switching," in Attention and Performance XVIII: Control of Cognitive Processes, eds S. Monsell and J. Driver (Cambridge, MA: MIT Press).

Green, J. P., Barabasz, A. F., Barrett, D., and Montgomery, G. H. (2005). Forging ahead: the 2003 APA Division 30 definition of hypnosis. Int. J. Clin. Exp. Hypn. 53, 259-264. doi: 10.1080/00207140590961321

Green, J. P., and Lynn, S. J. (2011). Hypnotic responsiveness: expectancy, attitudes, fantasy proneness, absorption, and gender. Int. J. Clin. Exp. Hypn. 59, 103-121. doi: 10.1080/00207144.2011.522914

$\mathrm{Gu}$, Q. (2002). Neuromodulatory transmitter systems in the cortex and their role in cortical plasticity. Neuroscience 111, 815-835. doi: 10.1016/S03064522(02)00026-X

Guevara-Guzman, R., Emson, P. C., and Kendrick, K. M. (1994). Modulation of in vivo striatal transmitter release by nitric oxide and cyclic GMP. J. Neurochem. 62, 807-810. doi: 10.1046/j.1471-4159.1994.62020807.x

Jambrik, Z., Santarcangelo, E. L., Ghelarducci, B., Picano, E., and Sebastiani, L. (2004). Does hypnotizability modulate the stress-related endothelial dysfunction? Brain Res. Bull. 63, 213-216. doi: 10.1016/j.brainresbull.2004.01.011

Jambrik, Z., Santarcangelo, E. L., Rudisch, T., Varga, A., Forster, T., and Carli, G. (2005). Modulation of pain-induced endothelial dysfunction by hypnotisability. Pain 116, 181-186. doi: 10.1016/j.pain.2005.03.041

Jamieson, G. A., and Sheehan, P. W. (2004). An empirical test of Woody and Bowers's dissociated-control theory of hypnosis. Int. J. Clin. Exp. Hypn. 52, 232-249. doi: $10.1080 / 0020714049052349$

Klinkenberg, I., Sambeth, A., and Blokland, A. (2011). Acetylcholine and attention. Behav. Brain Res. 221, 430-42. doi: 10.1016/j.bbr.2010.11.033

Lichtenberg, P., Bachner-Melman, R., Ebstein, R. P., and Crawford, H. J. (2004). Hypnotic susceptibility: multidimensional relationships with Cloninger's Tridimensional Personality Questionnaire, COMT polymorphisms, absorption, and attentional characteristics. Int. J. Clin. Exp. Hypn. 52, 47-72. doi: 10.1076/iceh.52.1.47.23922

Lichtenberg, P., Bachner-Melman, R., Gritsenko, I., and Ebstein, R. P. (2000). Exploratory association study between catechol-O-methyltransferase (COMT) high/low enzyme activity polymorphism and hypnotizability. Am. J. Med. Genet. 96, 771-774 doi: 10.1002/1096-8628(20001204)96:6<771::AIDAJMG14>3.0.CO;2-T

Löscher, W., Annies, R., and Hönack, D. (1991). The N-methyl-D-aspartate receptor antagonist MK-801 induces increases in dopamine and serotonin metabolism in several brain regions of rats. Neurosci. Lett. 128, 191-194. doi: 10.1016/03043940(91) $90258-\mathrm{U}$

Motulsky, H. (2010). Intuitive Biostatistics: A Nonmathematical Guide to Statistical Thinking. New York: Oxford University Press.

Nabeshima, T., Fukaya, H., Yamaguchi, K., Ishikawa, K., Furukawa, H., and Kameyama, T. (1987). Development of tolerance and supersensitivity to phencyclidine in rats after repeated administration of phencyclidine. Eur. J. Pharmacol. 135, 23-33. doi: 10.1016/0014-2999(87)90753-9

Nackley, A. G., Shabalina, S. A., Tchivileva, I. E., Satterfield, K., Korchynskyi, O., Makarov, S. S., et al. (2006). Human catechol-O-methyltransferase haplotypes modulate protein expression by altering mRNA secondary structure. Science 314 , 1930-1933. doi: 10.1126/science.1131262

Norman, D. A., and Shallice, T. (1986). "Attention to action," in Consciousness and Self-regulation, 1st Edn, eds R. J. Davidson, G. E. Schwartz, and D. Shapiro (New York: Plenum Press).

Ott, U., Reuter, M., Hennig, J., and Vaitl, D. (2005). Evidence for a common biological basis of the Absorption trait, hallucinogen effects, and positive symptoms: 
epistasis between 5-HT2a and COMT polymorphisms. Am. J. Med. Genet. B Neuropsychiatr. Genet. 137B, 29-32. doi: 10.1002/ajmg.b.30197

Pekala, R. J., and Forbes, E. J. (1997). Types of hypnotically (un)susceptible individuals as a function of phenomenological experience: towards a typology of hypnotic types. Am. J. Clin. Hypn. 39, 212-224. doi: 10.1080/00029157.1997.10403386

Posner, M. I., and Fan, J. (2004). "Attention as an organ system," in Topics in Integrative Neuroscience: From Cells to Cognition, ed. J. R. Pomerantz (Cambridge: Cambridge University Press).

Raz, A. (2005). Attention and hypnosis: neural substrates and genetic associations of two converging processes. Int. J. Clin. Exp. Hypn. 53, 237-258 doi: 10.1016/j.jphysparis.2006.03.003

Raz, A., Fan, J., and Posner, M. I. (2006). Neuroimaging and genetic associations of attentional and hypnotic processes. J. Physiol. Paris 99, 483-491. doi: 10.1080/00207140590961295

Roussos, P., Giakoumaki, S. G., Pavlakis, S., and Bitsios, P. (2008). Planning, decision-making and the COMT rs4818 polymorphism in healthy males. Neuropsychologia 46, 757-763. doi: 10.1016/j.neuropsychologia.2007.10.009

Schork, N. J., Nath, S. K., Fallin, D., and Chakravarti, A. (2000). Linkage disequilibrium analysis of biallelic DNA markers, human quantitative trait loci, and threshold-defined case and control subjects. Am. J. Hum. Genet. 67, 1208-1218. doi: 10.1086/321201

Seamans, J. K., and Yang, C. R. (2004). The principal features and mechanisms of dopamine modulation in the prefrontal cortex. Prog. Neurobiol. 74, 1-58. doi: 10.1016/j.pneurobio.2004.05.006

Sheehan, P. W., and McConkey, K. M. (1982). Hypnosis and Experience: The Exploration of Phenomena and Process. Hillsdale, NJ: Erlsbaum.

Spiegel, D., and King, R. (1992). Hypnotizability and CSF HVA levels among psychiatric patients. Biol. Psychiatry 31, 95-98. doi: 10.1016/0006-3223(92)90009-O

Szekely, A., Kovacs-Nagy, R., Bányai, E. I., Gosi-Greguss, A. C., Varga, K., Halmai, Z., et al. (2010). Association between hypnotizability and the catechol-Omethyltransferase (COMT) polymorphism. Int. J. Clin. Exp. Hypn. 58, 301-315. doi: 10.1080/00207141003760827

Tellegen, A., and Atkinson, G. (1974). Openness to absorbing and self-altering experiences ("absorption"), a trait related to hypnotic susceptibility. J. Abnorm. Psychol. 83, 268-277. doi: 10.1037/h0036681
Terhune, D. B., Cardeña, E., and Lindgren, M. (2011). Dissociated control as a signature of typological variability in high hypnotic suggestibility. Conscious. Cogn. 20, 727-736. doi: 10.1016/j.concog.2010.11.005

Terwilliger, J., and Ott, J. (1994). Handbook of Human Genetic Linkage. Baltimore: Johns Hopkins University Press.

Van Gestel, S., Houwing-Duistermaat, J. J., Adolfsson, R., van Duijn, C. M., and Van Broeckhoven, C. (2000). Power of selective genotyping in genetic association analyses of quantitative traits. Behav. Genet. 30, 141-146. doi: 10.1023/A:1001907321955

Varga, K., Németh, Z., and Szekely, A. (2011). Lack of correlation between hypnotic susceptibility and various components of attention. Conscious. Cogn. 20, 18721881. doi: 10.1016/j.concog.2011.09.008

Weitzenhoffer, A. M., and Hilgard, K. E. (1962). Stanford Hypnotic Susceptibility Scale, Form C. Palo Alto, CA: Stanford University Press.

Zachariae, R., Jørgensen, M. M., and Christensen, S. (2000). Hypnotizability and absorption in a Danish sample: testing the influence of context. Int. J. Clin. Exp. Hypn. 48, 306-314. doi: 10.1080/00207140008415248

Conflict of Interest Statement: The authors declare that the research was conducted in the absence of any commercial or financial relationships that could be construed as a potential conflict of interest.

Received: 24 August 2013; accepted: 20 December 2013; published online: 06 January 2014.

Citation: Presciuttini S, Gialluisi A, Barbuti S, Curcio M, Scatena F, Carli Gand Santarcangelo EL (2014) Hypnotizability and Catechol-O-Methyltransferase (COMT) polymorphysms in Italians. Front. Hum. Neurosci. 7:929. doi: 10.3389/fnhum.2013.00929 This article was submitted to the journal Frontiers in Human Neuroscience. Copyright (C) 2014 Presciuttini, Gialluisi, Barbuti, Curcio, Scatena, Carli and Santarcangelo. This is an open-access article distributed under the terms of the Creative Commons Attribution License (CC BY). The use, distribution or reproduction in other forums is permitted, provided the original author(s) or licensor are credited and that the original publication in this journal is cited, in accordance with accepted academic practice. No use, distribution or reproduction is permitted which does not comply with these terms. 